\title{
Rheological Evaluation of Modified Bitumen by EVA and Crumb Rubber Using RSM Optimization
}

\author{
Mohamad H. Dehnad $\left(\mathbb{D},{ }^{1}\right.$ Behrouz Damyar $\mathbb{D}^{\circ},{ }^{2}$ and Hossein Z. Farahani ${ }^{3}{ }^{3}$ \\ ${ }^{1}$ Department of Civil Engineering, University of Qom, Qom 3716146611, Iran \\ ${ }^{2}$ Road Maintenance and Transport Organization, Tehran 1416753941, Iran \\ ${ }^{3}$ Department of Civil Engineering, University of Tafresh, Tafresh 3951879611, Iran \\ Correspondence should be addressed to Mohamad H. Dehnad; m.dehnad@qom.ac.ir
}

Received 6 May 2021; Accepted 23 July 2021; Published 19 August 2021

Academic Editor: Youhong Tang

Copyright ( $\odot 2021$ Mohamad H. Dehnad et al. This is an open access article distributed under the Creative Commons Attribution License, which permits unrestricted use, distribution, and reproduction in any medium, provided the original work is properly cited.

\begin{abstract}
In the present study, ethylene-vinyl acetate (EVA) and crumb rubber (CR) were used as bitumen modifiers. The experiment was designed by response surface methodology (RSM) at different levels of modifier additives based on the central composite design (CCD). Next, the Superpave protocol was followed to evaluate the modified bitumen performance at different temperatures compared with the unmodified bitumen. In this regard, to evaluate at high temperatures, a dynamic shear rheometer (DSR) test was performed, and $G^{*} / \sin \delta$ index was examined on bitumen samples after aging. Besides, the bending beam rheometer (BBR) test was performed to evaluate the low-temperature behaviour of the modified bitumen according to the SHRP standard based on the creep stiffness and creep rate. The optimal combination of additives was evaluated using RSM and analysis of statistical values to improve the performance properties of bitumen at high and low temperatures. Moreover, based on the DSR and BBR test results, $5.6 \%$ of EVA and $3.9 \%$ of CR were selected as the optimal values for the modified bitumen behaviour at the high and low temperatures of the mixture.
\end{abstract}

\section{Introduction}

Various studies have shown that mixing polymer additives and crumb rubber to bitumen has significantly changed the properties and rheology of bitumen and thus asphalt concrete. Modified polymer bitumen has reduced the thermal sensitivity of bitumen and improved the durability of stripping. Furthermore, asphalt mixtures containing modified polymer bitumen are resistant to many deformations and stresses applied to the pavement. Crumb rubbermodified bitumen has also shown several advantages, including lower temperature sensitivity, higher viscosity at higher temperatures, and more flexibility at lower temperatures. According to previous studies, it has been found that asphalt mixtures produced with this type of bitumen have good resistance against rutting, permanent deformations, and fatigue cracking. Also, these mixtures have higher resistance against reflective cracks [1-4].
Morales et al. [5] studied several polymer combination effects on the rheological behaviour of bitumen. They concluded that rheological improvement could be achieved at high and low temperatures by mixing polyolefin with crumb rubber. They found that $3.5 \%$ of ethylene-vinyl acetate and 3.5\% rubber can be the best mixture to provide better bitumen behaviour in a wide range of temperatures [5]. In another study, two types of dry and wet mixtures were used to add polymer wastes to bitumen and asphalt mixtures. This study concluded that wet mixing produces a more uniform and operational asphalt mixture. Also, based on the main tests of bitumen, it was pointed out that a mixture of $4 \%$ polyethylene and $4 \%$ rubber powder can be a suitable combination for mixing with bitumen [6].

Ameri et al. [7] investigated the effect of mixing different percentages of ethylene-vinyl-acetate polymer on the bitumen of the Iranian 60/70 refinery. They found that, with increasing percentage of ethylene-vinyl acetate, the creep 
stiffness decreases and the creep rate increases. Furthermore, they concluded that a sample containing $4 \%$ polymer has the best performance in the mixture. Feng et al. [8] investigated the storage stability of polyethylene waste used to modify bitumen properties using microscopic analysis and hightemperature storage stability. They concluded that the bitumen mixture prepared at a temperature of $150^{\circ} \mathrm{C}$ and a mixing speed of $3750 \mathrm{rpm}$ using a high-speed shear mixer for 1.5 hours is the best mixture for storage stability.

Toth et al. [9] proposed a new approach to the compatibility of polyethylene waste and rubber powder compounds using additives based on olefin-maleic-anhydride copolymer. In another study, they investigated the rheological properties of EVA-modified bitumen and their relationship with the properties of the bitumen mixture. They concluded that the rheological modification of bitumen by EVA depends on the grade of bitumen [10]. Sakinah et al. [11] investigated the effect of mixing conditions on the tensile properties of the combination of ethylene-vinyl-acetate and rubber powder produced from tire waste. Another study was conducted to evaluate the performance and mechanical behaviour of EVA-modified bitumen mixtures and EVA waste [12].

Namade et al. [6] considered a combination of waste rubber powder and heavy polyethylene, and by performing only initial bitumen tests, they concluded that a combination of $4 \%$ light polyethylene and $4 \%$ rubber powder might be appropriate. In research conducted by Yousefi [13], rubber powder and other materials such as H.V.S light oil polyethylene were added to the bitumen. Several tests, including softening point, penetration grade, Fraass breaking point, stability, and morphology, were performed on the produced samples. Results showed that increasing the amount of rubber powder increases the softening point and decreases the penetration. Moreover, the optimal composition is obtained with $13 \%$ rubber powder, $5 \%$ oil, and $3 \%$ polyethylene [13].

Arabani et al. [14] used 60/70 bitumen and rubber powder to prepare bitumen and evaluate different aromatic oil percentages. Stiffness, fatigue, and creep modulus tests were performed on the samples by the Nottingham Asphalt Tester. It was found that the addition of aromatic oil to rubber bitumen samples increased fatigue life, modulus of stiffness, and creep stiffness; however, it reduced axial and vertical deformation. Tabatabai et al. [15] evaluated the viscosity of VB bitumen against increasing the amount of rubber powder at different temperatures. They investigated the effect of rubber powder as an additive on the rotational viscosity of bitumen. Zhang and $\mathrm{Hu}$ [16] studied the modified bitumen by combining rubber powder and waste plastic using rheological tests to investigate the high- and low-temperature properties and structural characteristics of the modified binder. Simultaneous application of EVA and SBS polymer and evaluation of microstructural characteristics of modified bitumen were performed in Sangoz and Isikikar study [17].

RSM statistical technique has been used in several pieces of research to optimize and investigate the interaction of different factors. Various studies have been reviewed in recent years in the field of bitumen and asphalt mixtures. In a study, waste rubber and glass fibber were modeled by Yildirim and Karacasu [18] with a response surface method in hot mix asphalt. They concluded that the statistical model could be used to obtain the most informative models. Moreover, they showed that a simultaneous multivariable optimization process determines the optimum values of all parameters.

Moreover, Badri et al. [19] applied the response surface methodology technique and investigated the rheological properties of asphalt binders incorporating different crumb rubber contents. They performed a temperature sweep test on modified binders with various crumb rubber contents using a dynamic shear rheometer (DSR). RSM statistical analysis was conducted based on the central composite design (CCD), assuming the rheological parameters complex modulus $\left(G^{*}\right)$ and phase angle $\left(\delta^{\circ}\right)$ as response variables.

In another study, the effect of bitumen chemical composition, elastomeric polymer, and paraffin wax additives on the properties of bitumen was examined using the response surface method. Besides, shear rheometer, viscosity, elasticity, and creep stiffness were used as responses [20]. Khairuddin et al. optimized the physical and chemical analyses of the modified polyurethane bitumen using the response surface methodology [21]. Jiminez et al. used the response surface methodology to optimize the final blends for liquid rubber modified bitumen for road pavements [22].

Furthermore, other pieces of research have been conducted with the RSM technique in the field of asphalt mixtures. Usman et al. investigated the polyethylene terephthalate fiber and binder content optimization for fiberreinforced asphalt mix using response surface methodology [23]. Haghshenas et al. studied the frequency and temperature interactive effects on hot mix permanent deformation using RSM [24].

\section{Materials and Methods}

EVA polymer in the range of 3 to $7 \%$ and CR in the range of 2 to $6 \%$ were selected for mixing with bitumen (Iranian refinery bitumen) to investigate the effect of ethylene-vinyl acetate and crumb rubber on bitumen properties. Initially, the experimental design was performed by the central composite design (CCD) method in 13 runs and one block using the response surface methodology.

Subsequently, a high shear mixer with a mixing cycle of $3750 \mathrm{rpm}$ was used for 90 minutes at $150^{\circ} \mathrm{C}$ to ensure the uniformity of the polymer-bitumen mixture. Classical tests, including penetration grade and softening point, were performed. Next, the dynamic shear rheometer test was carried out based on the relevant standard. Moreover, the bending beam rheometer (BBR) test was performed by measuring the creep stiffness and creep rate indices following Superpave instructions to evaluate the behaviour of bitumen modified at low temperatures.

The characteristics of the initial bitumen and the results of classical and SHRP experiments are presented in Table 1. Different combinations of bitumen produced, based on the 
TABle 1: Characteristics of unmodified bitumen.

\begin{tabular}{lcccccccc}
\hline & \multicolumn{4}{c}{ Classical test } & \multicolumn{2}{c}{ DSR test } & BBR test \\
& $\begin{array}{c}\text { Softening } \\
\text { point }\left({ }^{\circ} \mathrm{C}\right)\end{array}$ & $\begin{array}{c}\text { Penetration } \\
(\mathrm{dmm})\end{array}$ & $\begin{array}{c}\text { Ductility } \\
(\mathrm{cm})\end{array}$ & $\begin{array}{c}\text { Viscosity at } \\
135^{\circ} \mathrm{C}(\mathrm{Pa} \cdot \mathrm{s})\end{array}$ & $\begin{array}{c}\text { Temp for } \\
G^{*} / \sin \delta \geq 2.2 \mathrm{kPa} \\
\left({ }^{\circ} \mathrm{C}\right)\end{array}$ & $\begin{array}{c}\text { Temp for } \\
G^{*} / \text { sin } \delta \leq 5000 \mathrm{kPa} \\
\left({ }^{\circ} \mathrm{C}\right)\end{array}$ & $\begin{array}{c}\text { Creep } \\
\text { stiffness }\end{array}$ & $m$-value \\
\hline $\begin{array}{l}\text { Unmodified } \\
\text { bitumen }\end{array}$ & 47.2 & 93 & +100 & 0.41 & 62.21 & 22 & 70 & 0.36 \\
\hline
\end{tabular}

experimental design, the results of penetration and softening point tests, and the outputs of DSR and BBR tests are presented in Table 2.

\section{Results and Discussion}

3.1. Classical Tests. The measurement of the bitumen penetration grade test and the softening point were according to the ASTM-D5 and ASTM-D36 standards sequentially. The penetration grade test determines the relative stiffness of the bitumen. The softening point test measures the temperature at which the bitumen flows. Bitumen with a higher degree of softness is less sensitive to temperature changes, and its viscosity changes less.

According to Figure 1, it is evident that, by increasing the amount of EVA polymer and CR to bitumen, the bitumen penetration grade decreases, and the softening point increases. As can be seen, more than 5\% EVA and more than $4 \% \mathrm{CR}$ reduce the penetration grade. More than $6 \% \mathrm{EVA}$ and more than $4.5 \% \mathrm{CR}$ increase the softening point. Reducing the penetration grade means reducing the flow and increasing the durability at high and medium temperatures. The polymer bitumen at high temperatures prevents the asphalt mixture from cracking. A similar conclusion was reached by Ameri et al. [25]. Moreover, the findings are directly in line with previous findings [26, 27].

The penetration index (PI) method calculates the thermal sensitivity of bitumen. Increasing the EVA and CR by different percentages increases the bitumen PI, but the amount is not the same for each compound.

Tables 3 and 4 show the conduction of ANOVA analysis and regression coefficients for penetration grade and softening point. Based on the $P$ value, the interaction between the variables and the CR square in the penetration grade was insignificant, but it was significant for the EVA square. Also, based on regression coefficients, the amount of EVA and CR have a similar effect on reducing the penetration. The regression correlation in the soft point is linear, and the squares of the variables and the interaction are not significant. EVA also has a greater effect on raising the softening point than CR.

3.1.1. SHRP Tests. In this section, the conduction of DSR, BBR, RTFO (rolling thin film oven), and PAV (pressure aging vessel) tests are according to the SHRP standard. The DSR test results confirm that the EVA and CR make high bitumen temperature functions better. There was a shortterm aging test conduction on samples in the RTFO chamber. Figure 2 presents the temperature at which
$G^{*} / \operatorname{Sin} \delta$ (rutting factor) reaches at least $2.2 \mathrm{kPa}$ for aged specimens. As shown in Figure 2, the EVA and RC increase the bitumen temperature. The parameter $G^{*} / \operatorname{Sin} \delta$ predicts the rutting failure at high temperatures. Figure 3 shows the addition of these polymers to the bitumen has improved the asphalt rutting criteria. This result indicates better bitumen functions at high temperatures and reduced rutting failure in asphalt mixtures. According to Figure 2, in the EVA percentage of about 5.8, a temperature of approximately $82^{\circ} \mathrm{C}$ is obtained. Based on SHRP functional requirement, it is equivalent to the maximum high temperature of bitumen.

The PAV test assumes long-term aging (during service) according to the ASTM D6521 standard method, in which the exposure of the binder is to high pressure and temperature for 20 hours. After this test, the $G^{*} / \operatorname{Sin} \delta$ parameter, which is the measure of fatigue cracks at medium temperatures, should be less than $5000 \mathrm{kPa}$ for all samples at the DSR test temperature. Therefore, for all samples, the minimum temperature with the parameter $G^{*} / \operatorname{Sin} \delta<5000 \mathrm{kPa}$ is shown in Figure 4. As can be recognized, in samples, less than $5 \%$ of the polymer reaches $5000 \mathrm{kPa}$ at lower temperatures than the unmodified bitumen. Therefore, in these samples, the improvement of the medium temperature of bitumen in which fatigue cracks occur is observed.

In samples containing less than $4 \%$, the better functions are observed, but in other samples, by increasing the percentage of polymer and rubber powder, because it induces bitumen to harden, these samples reach the value of $5000 \mathrm{kPa}$ at higher temperatures than the unmodified bitumen and, therefore, may not be suitable for cold regions. According to the obtained results and comparison of $G^{*} / \operatorname{Sin} \delta$ factor (fatigue factor), for all samples, the conclusion is that the sample containing less than 5\% EVA and $5 \%$ rubber powder has a better function at low temperatures.

Tables 5 and 6 present the ANOVA analysis and regression coefficients for high and low temperatures. As can be detected, there is no interaction effect between the parameters, and for high and low temperatures, there is a suggestion for two linear regression relationships:

$$
\operatorname{Temp}\left(\frac{G^{*}}{\sin \delta} \geq 2.2 \mathrm{kPa}\right)=56.93+5.4 \times \mathrm{EVA}+2.3 \times \mathrm{CR},
$$

$\operatorname{Temp}\left(G^{*} \cdot \operatorname{Sin} \delta \leq 5000 \mathrm{kPa}\right)=3.16+4.64 \times \mathrm{EVA}-2.39 \times \mathrm{CR}$.

In Figure 5, the parameters related to the operation at high and low temperatures are investigated. If the high operating temperature of bitumen ranges from 80 to $82^{\circ} \mathrm{C}$ 
TABle 2: Central composite design arrangement and responses.

\begin{tabular}{|c|c|c|c|c|c|c|c|c|}
\hline \multirow{2}{*}{ Run } & \multicolumn{2}{|c|}{ Factors } & \multicolumn{6}{|c|}{ Responses } \\
\hline & EVA (\%) & CR (\%) & Pen & Soft & $\operatorname{Temp}\left(G^{*} / \sin \delta \geq 2.2 \mathrm{kPa}\right)$ & $\operatorname{Temp}\left(G^{*} / \sin \delta \leq 5000 \mathrm{kPa}\right)$ & Creep stiffness & $m$-Value \\
\hline 1 & 3 & 2 & 54.5 & 58 & 82.00 & 25 & 134.9 & 0.234 \\
\hline 11 & 5 & 4 & 52 & 67 & 78.00 & 18 & 79.9 & 0.288 \\
\hline 8 & 5 & 6 & 49 & 72 & 80.00 & 19 & 75.4 & 0.321 \\
\hline 7 & 5 & 2 & 54 & 64 & 79.00 & 16 & 73.4 & 0.313 \\
\hline 4 & 7 & 6 & 40 & 80 & 82.00 & 25 & 151.6 & 0.264 \\
\hline 2 & 7 & 2 & 51 & 72 & 82.00 & 22 & 108.8 & 0.277 \\
\hline 12 & 5 & 4 & 52 & 67 & 73.15 & 15 & 66.3 & 0.372 \\
\hline 6 & 7 & 4 & 45 & 74 & 80.00 & 19 & 75.4 & 0.321 \\
\hline 9 & 5 & 4 & 52 & 67 & 81.00 & 20 & 76.4 & 0.331 \\
\hline 5 & 3 & 4 & 53.5 & 59 & 79.00 & 18 & 74.4 & 0.311 \\
\hline 10 & 5 & 4 & 52 & 67 & 80.00 & 19 & 75.4 & 0.321 \\
\hline 13 & 5 & 4 & 52 & 67 & 82.00 & 23 & 128.0 & 0.281 \\
\hline 3 & 3 & 6 & 50 & 61 & 77.00 & 8 & 62.3 & 0.391 \\
\hline
\end{tabular}
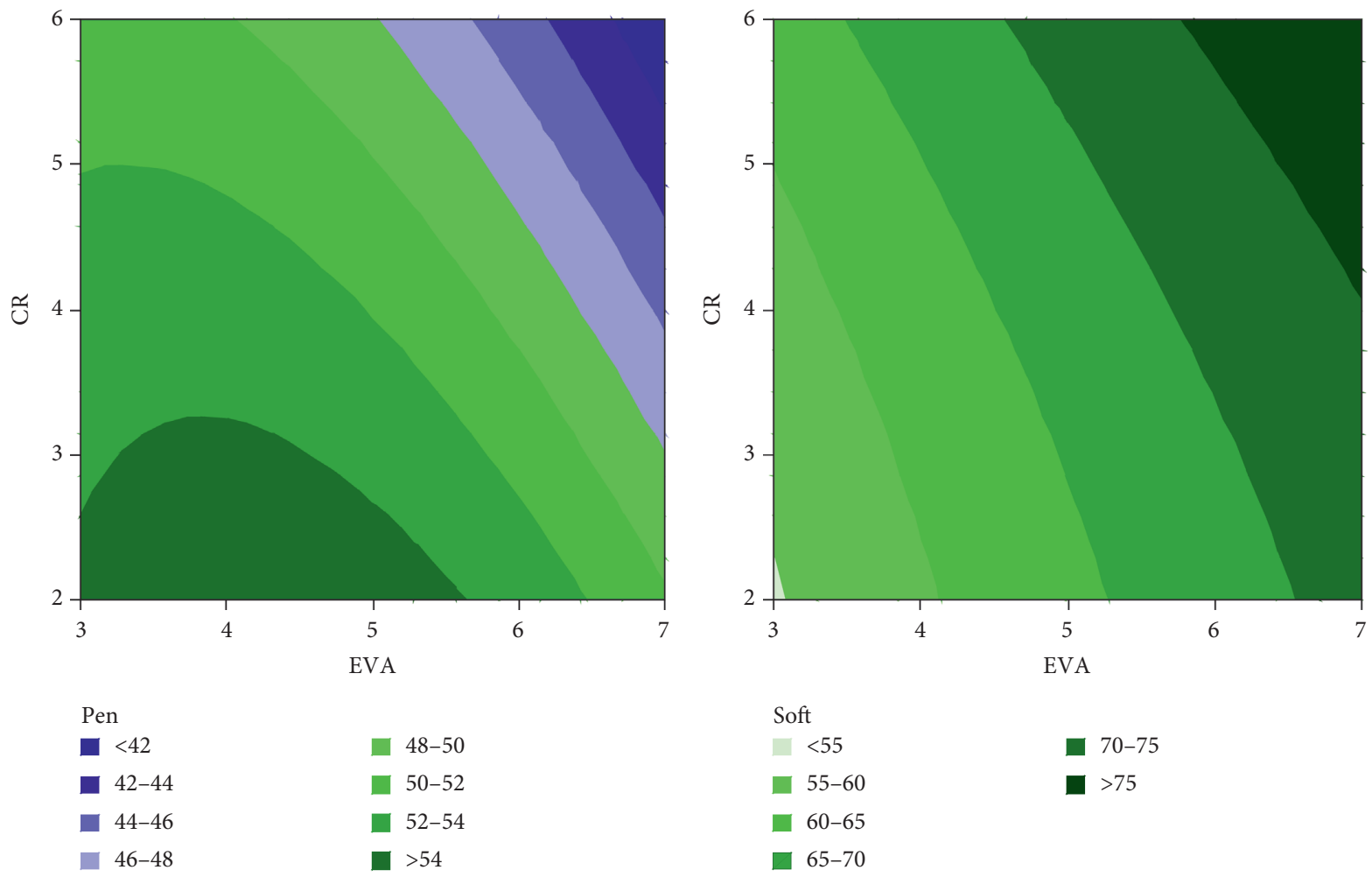

(a)

(b)

FIgURE 1: Contour plot of penetration grade and softening point. (a) Contour plot of pen vs. CR and EVA. (b) Contour plot of soft vs. CR and EVA.

TABLE 3: ANOVA table for penetration grade and softening point tests.

\begin{tabular}{|c|c|c|c|c|c|c|c|c|c|c|}
\hline \multirow{2}{*}{ Regression characteristics } & \multicolumn{5}{|c|}{ Penetration grade } & \multicolumn{5}{|c|}{ Softening point } \\
\hline & $\mathrm{DF}$ & SS & MS & $F$-value & $P$ value & $\mathrm{DF}$ & SS & MS & $F$-value & $P$ value \\
\hline Regression & 5 & 186.758 & 37.3516 & 45.53 & $\leq 0.001$ & 5 & 531.751 & 106.35 & 143.93 & $\leq 0.001$ \\
\hline Linear & 2 & 150.708 & 75.3542 & 91.86 & $\leq 0.001$ & 2 & 529.5 & 264.75 & 358.29 & $\leq 0.001$ \\
\hline Square & 2 & 25.487 & 12.7435 & 15.54 & 0.003 & 2 & 2.251 & 1.125 & 1.52 & 0.282 \\
\hline Interaction & 1 & 10.562 & 10.5625 & 12.88 & 0.5 & 1 & 0 & 0 & 0 & 1 \\
\hline Residual error & 7 & 5.742 & 0.8203 & & & 7 & 0 & 0.739 & & \\
\hline Lack-of-fit & 3 & 3.542 & 1.1807 & 2.15 & 0.237 & 3 & 5.172 & 1.057 & 2.11 & 0.241 \\
\hline Pure error & 4 & 2.2 & 0.55 & & & 4 & 3.172 & 0.5 & & \\
\hline $\mathrm{R}-\mathrm{Sq}$ & & & 97.02 & & & & & 99.04 & & \\
\hline
\end{tabular}

Note. DF, degrees of freedom; SS, sum of squares; MS, mean square. 
TABLE 4: Values of regression coefficients calculated for penetration grade and softening point tests.

\begin{tabular}{|c|c|c|c|c|c|c|c|c|}
\hline \multirow{2}{*}{ Term } & \multicolumn{4}{|c|}{ Penetration grade } & \multicolumn{4}{|c|}{ Softening point } \\
\hline & Coef & SE coef & $T$-value & $P$ value & Coef & SE coef & $T$-value & $P$ value \\
\hline Constant & 51.8966 & 0.3761 & 137.996 & $\leq 0.001$ & 67.069 & 0.3569 & 187.905 & $\leq 0.001$ \\
\hline EVA & -3.6667 & 0.3698 & -9.917 & $\leq 0.001$ & 8.5 & 0.3509 & 24.221 & $\leq 0.001$ \\
\hline $\mathrm{CR}$ & -3.4167 & 0 & -9.24 & $\leq 0.001$ & 4 & 0.3509 & 11.398 & $\leq 0.001$ \\
\hline EVA * EVA & -2.6379 & 0.3698 & -4.84 & 0.002 & -0.7414 & 0.5172 & -1.433 & 0.195 \\
\hline $\mathrm{CR}^{*} \mathrm{CR}$ & -0.3879 & 0.545 & -0.712 & 0.5 & 0.7586 & 0.5172 & 1.467 & 0.186 \\
\hline EVA *CR & -1.625 & 0.545 & -3.588 & 0.009 & 0 & 0.4298 & 0 & 1 \\
\hline
\end{tabular}
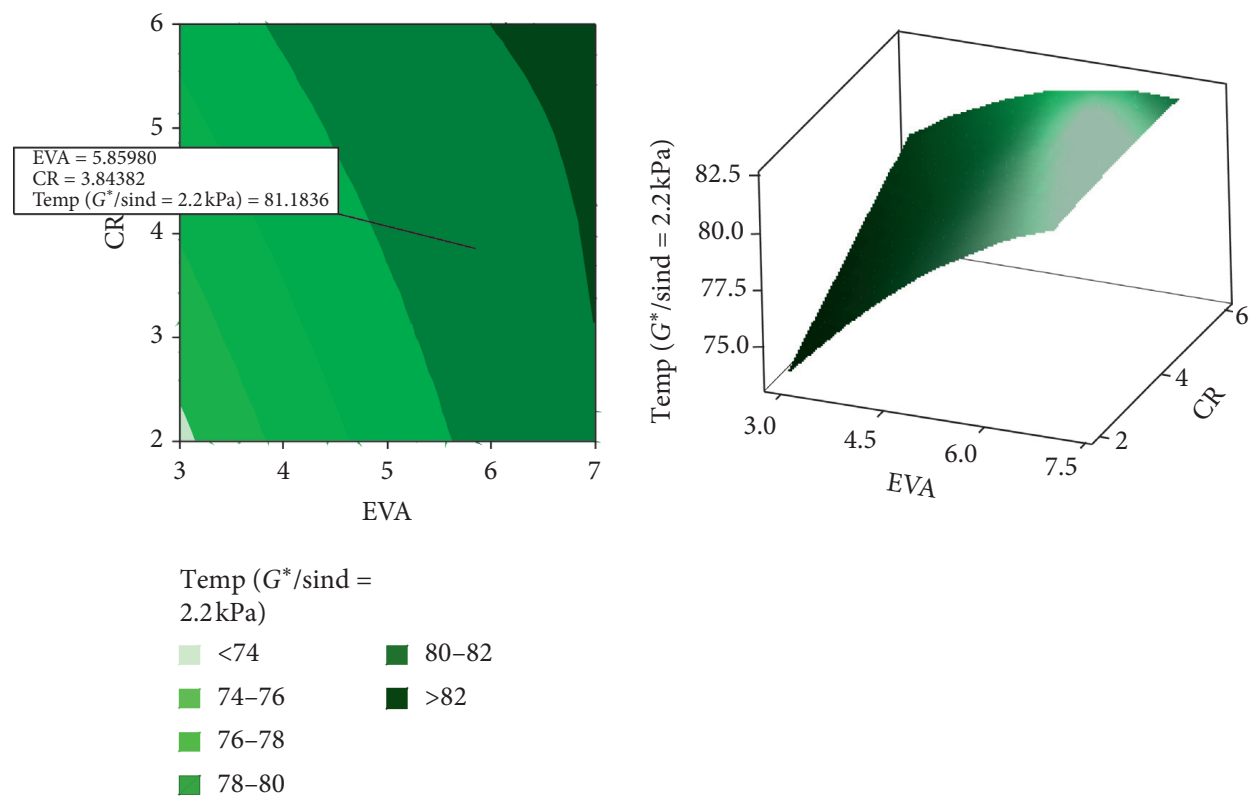

(a)

(b)

FIGURE 2: Contour plot of DSR test (rutting factor). (a) Contour plot of temp ( $G^{*} / \sin d \geq 2.2 \mathrm{kPa}$ ) vs. CE and EVA. (b) Surface plot of temp $\left(G^{*} / \sin d \geq 2.2 \mathrm{kPa}\right)$ vs. CE and EVA.

and the low operating temperature of bitumen ranges from 12 to $20^{\circ} \mathrm{C}$, a range of EVA and CR percentages that achieve these two conditions simultaneously is determined. For example, with 5.2\% EVA and $4.1 \% \mathrm{CR}$, the operating temperature range is 19 to $81^{\circ} \mathrm{C}$.

A bending beam rheometer (BBR) test evaluated the lowtemperature modified bitumen, and there was a comparison with the unmodified bitumen. The BBR test confirms that the combination of the above additives in some levels has improved the functional characteristics of low-temperature bitumen compared to unmodified bitumen. In the BBR test, applying a constant load to the bitumen beam and measuring the main beam deviation during the test period can calculate creep stiffness $(S)$ and creep rate $(m)$. The creep load simulates the thermal stresses that occur gradually with decreasing temperature in a road. Creep stiffness is the binder resistance to creep loading, and its value is the amount of change in bitumen stiffness with time (during loading).

The creep stiffness for unmodified samples was 70 . The lightest spectral range is approximately 3.5\% EVA and 3.5\% $\mathrm{CR}$, and it is smaller than $60 \%$ which indicates an improvement in the low-temperature bitumen compared to the unmodified bitumen; that is, the bitumen mixture has good elasticity at low temperatures. However, the creep stiffness development compared with unmodified bitumen for other percentages different from this range means that these lowtemperature samples are worse than the unmodified bitumen.

Using the RSM method, equation (2) determines the creep stiffness concerning the percentage of EVA and CR:

$$
\begin{aligned}
\text { Creep stiffness }= & 147.905-33.86 \times \mathrm{EVA}-20.9 \times \mathrm{CR} \\
& +4.85 \times \mathrm{EVA}^{2}+3 \times \mathrm{CR}^{2} .
\end{aligned}
$$

Figure 3 shows the values of creep stiffness and $m$-value; in the range of less than $4 \%$ EVA and less than $4 \% \mathrm{CR}$, the change rate of creep stiffness (creep rate) compared to the unmodified bitumen has increased, which has improved the potential for crack resistance at low temperatures. Therefore, the softness of the modified bitumen at low temperatures increases at a higher rate, but for other specimens, the creep rate decreases slightly, which may be as a result of the complete dominance of the polymer phase and hardening of 

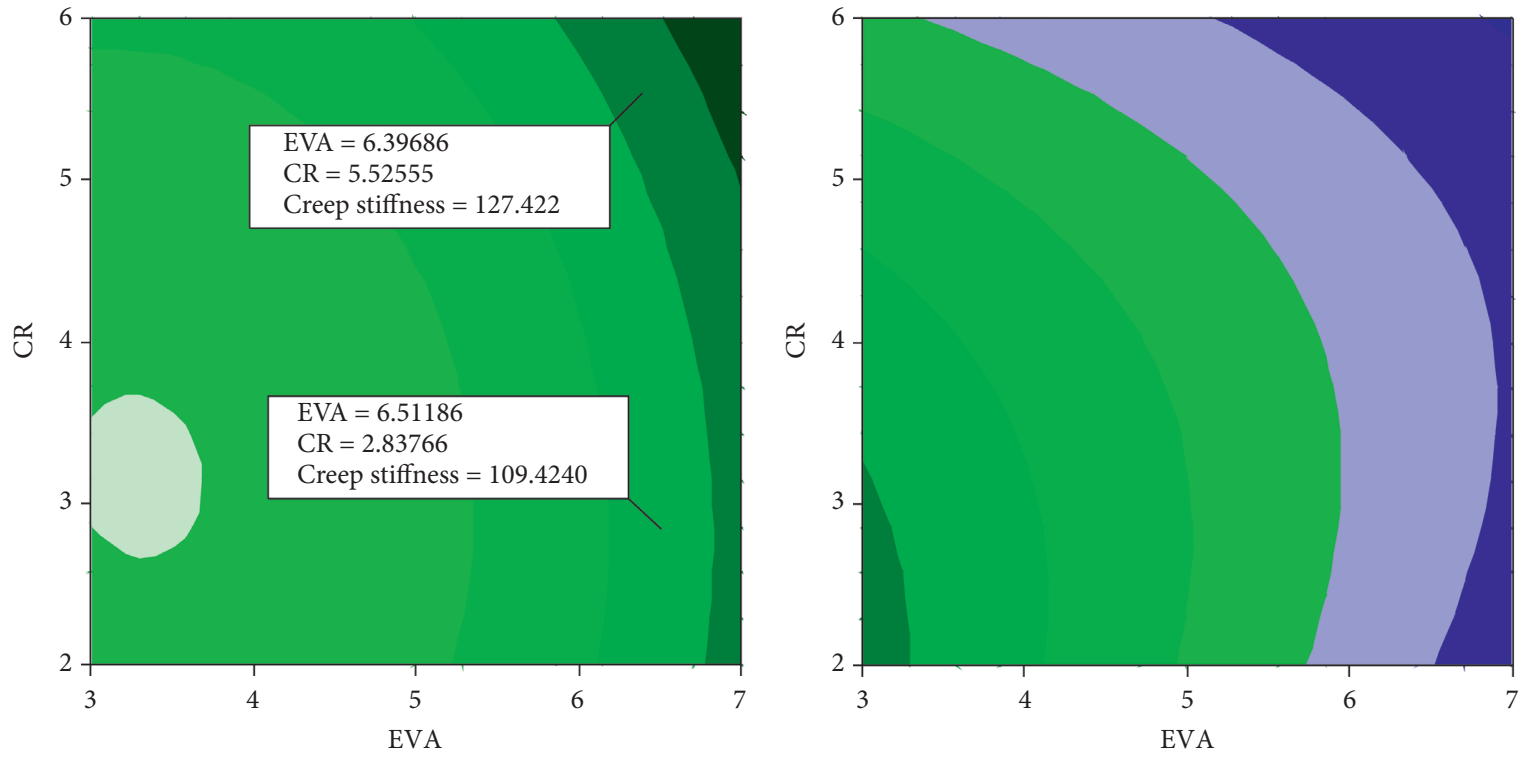

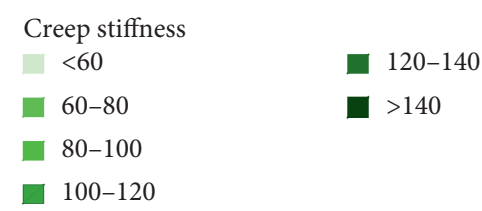

(a)

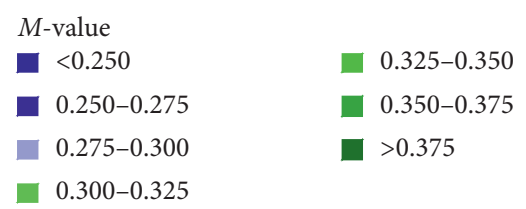

(b)

FIgUre 3: Contour plot of BBR tests. (a) Contour plot of creep stiffness vs. CR and EVA. (b) Contour plot of $m$-value vs. CR and EVA.

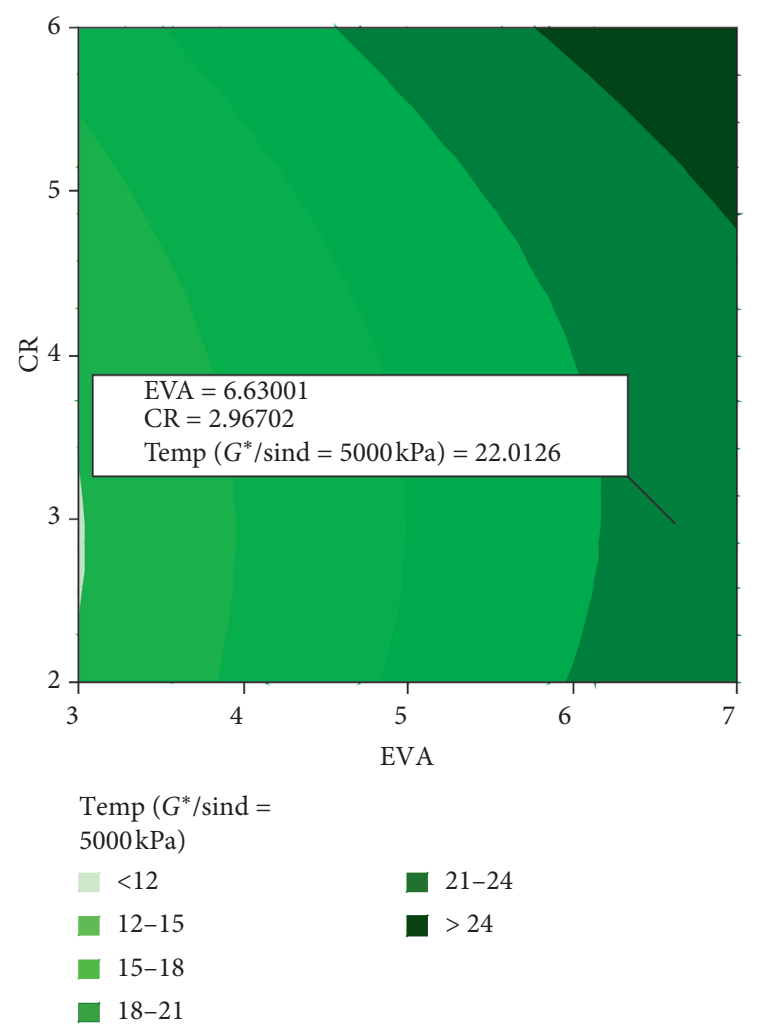

(a)

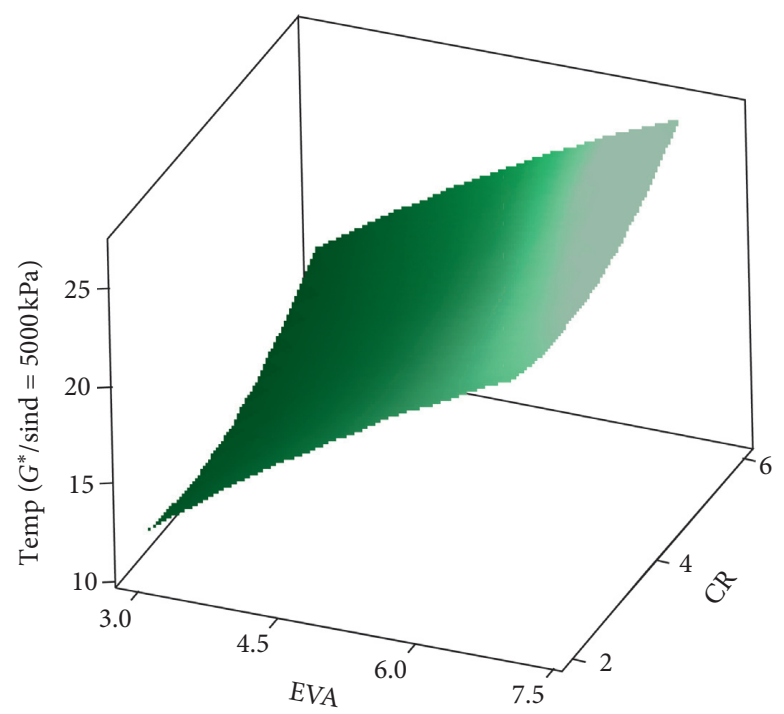

(b)

FIgUre 4: Contour plot of DSR test (fatigue factor). (a) Contour plot of temp ( $\left.G^{*} / \operatorname{Sin} d \leq 5000 \mathrm{kPa}\right)$ vs. CE and EVA. (b) Surface plot of temp $\left(G^{*} / \operatorname{Sin} d \leq 5000 \mathrm{kPa}\right)$ vs. CE and EVA. 
TABLE 5: ANOVA table for DSR tests.

\begin{tabular}{|c|c|c|c|c|c|c|c|c|c|c|}
\hline \multirow{2}{*}{ Regression characteristics } & \multicolumn{5}{|c|}{$\operatorname{Temp}\left(G^{*} / \sin \delta \geq 2.2 \mathrm{kPa}\right)$} & \multicolumn{5}{|c|}{$\operatorname{Temp}\left(G^{*} / \sin \delta \leq 5000 \mathrm{kPa}\right)$} \\
\hline & DF & SS & MS & $F$-value & $P$ value & DF & SS & MS & $F$-value & $P$ value \\
\hline Regression & 5 & 73.3121 & 14.6624 & 27.00 & $\leq 0.001$ & 5 & 200.135 & 40.027 & 6.11 & 0.017 \\
\hline Linear & 2 & 63.3742 & 31.6871 & 58.36 & $\leq 0.001$ & 2 & 190.833 & 95.417 & 14.56 & 0.003 \\
\hline Square & 2 & 4.0573 & 2.0287 & 3.74 & 0.079 & 2 & 9 & 4.526 & 0.69 & 0.532 \\
\hline Interaction & 1 & 5.8806 & 5.8806 & 10.83 & 0.013 & 1 & 0.052 & 0.250 & 0.04 & 0.851 \\
\hline Residual error & 7 & 3.8010 & 0.5430 & & & 7 & 0.250 & 6.552 & & \\
\hline Lack-of-fit & 3 & 1.8010 & 0.6003 & 1.20 & 0.416 & 3 & 45.865 & 14.622 & 29.24 & 0.004 \\
\hline Pure error & 4 & 2.0000 & 0.5000 & & & 4 & 43.865 & 0.500 & & \\
\hline $\mathrm{R}-\mathrm{Sq}$ & & & $95.07 \%$ & & & & & $81.36 \%$ & & \\
\hline
\end{tabular}

TABLE 6: Values of regression coefficients calculated for DSR tests.

\begin{tabular}{|c|c|c|c|c|c|c|c|c|}
\hline \multirow{2}{*}{ Term } & \multicolumn{4}{|c|}{$\operatorname{Temp}\left(G^{*} / \sin \delta \geq 2.2 \mathrm{kPa}\right)$} & \multicolumn{4}{|c|}{$\operatorname{Temp}\left(G^{*} / \sin \delta \leq 5000 \mathrm{kPa}\right)$} \\
\hline & Coef & SE coef & $T$-value & $P$ value & Coef & SE coef & $T$-value & $P$ value \\
\hline Constant & 80.1672 & 0.3060 & 262.006 & $\leq 0.001$ & 18.4828 & 1.063 & 17.390 & $\leq 0.001$ \\
\hline EVA & 2.9750 & 0.3008 & 9.889 & $\leq 0.001$ & 5.3333 & 1.045 & 5.104 & 0.001 \\
\hline $\mathrm{CR}$ & 1.3083 & 0.3008 & 4.349 & 0.003 & 1.8333 & 1.045 & 1.754 & 0.123 \\
\hline $\mathrm{EVA} * \mathrm{EVA}$ & -1.0853 & 0.4434 & -2.448 & 0.044 & -0.6897 & 1.540 & -0.448 & 0.668 \\
\hline $\mathrm{CR} * \mathrm{CR}$ & -0.0853 & 0.4434 & -0.192 & 0.853 & 1.8103 & 1.540 & 1.175 & 0.278 \\
\hline $\mathrm{EVA} * \mathrm{CR}$ & -1.2125 & 0.3684 & -3.291 & 0.013 & -0.2500 & 1.280 & -0.195 & 0.851 \\
\hline
\end{tabular}

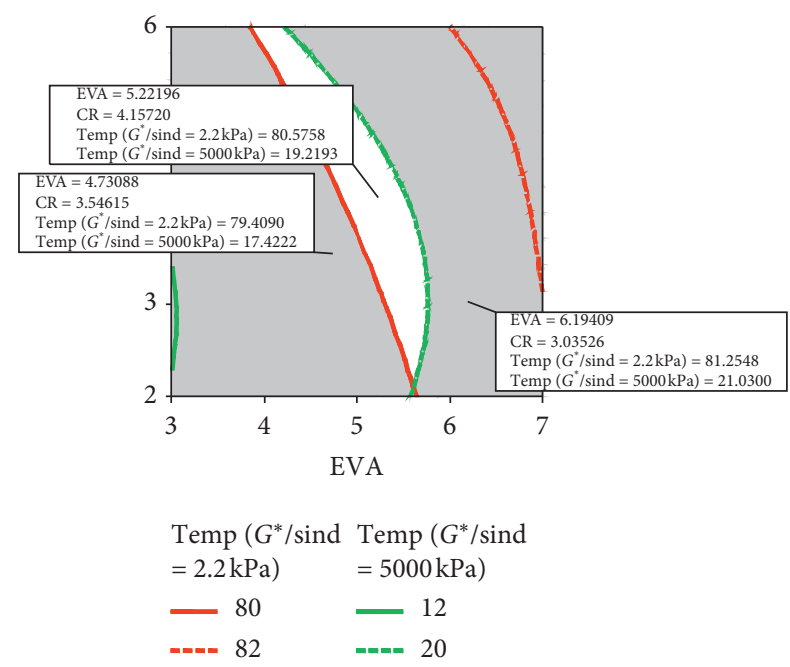

Figure 5: Contour plot of temperature $\left(G^{*} / \sin \delta \geq 2.2 \mathrm{kPa}\right.$ and $\left.G^{*} / \sin \delta \leq 5000 \mathrm{kPa}\right)$.

bitumen. This has led to the lower temperature degradation of these samples compared to the unmodified bitumen. According to SHRP instructions, creep stiffness values less than 300 and $m$-value greater than 0.3 indicate that the bitumen threshold is $10^{\circ} \mathrm{C}$ lower than the test temperature. The results demonstrated in this section match state-of-theart methods [7, 25, 28].

\section{Conclusions}

Pure bitumen has a limited cohesion despite its good adhesion and has a temperature limit between the breaking point and the softening point. The usage of these polymers expands the tolerable temperature range to more than twice that of unmodified bitumen while improving cohesion, which in turn enhances the resistance to flow, softening point, and higher viscosity under service conditions and reduces thermal sensitivity. A higher PI value indicates a lower thermal sensitivity of bitumen, and this shows that this type of bitumen can give more desirable properties in areas with high thermal differences. The classical test results proved that more than 5\% EVA and more than $4 \% \mathrm{CR}$ reduce the penetration grade. More than $6 \% \mathrm{EVA}$ and more than $4.5 \% \mathrm{CR}$ raise the softening point, as well.

The DSR test shows that samples less than 5\% polymer reach $5000 \mathrm{kPa}$ at lower temperatures than the unmodified bitumen, and the samples containing less than 5\% EVA and $5 \%$ rubber powder have a better function at low temperatures. Moreover, in this research, two linear regression relationships are proposed for high and low temperatures. SHRP test showed that, with 5.2\% EVA and $4.1 \% \mathrm{CR}$, the functional grade of modified bitumen is PG $82-10$.

BBR test determined that the combination of the above additives improves the functional characteristics of lowtemperature bitumen compared to unmodified bitumen. Thus, by increasing the percentage of ethylene-vinyl-acetate (EVA) polymer to $3 \%$ and crumb rubber to $4 \%$, respectively, the creep hardness decreases, and the creep rate increases. Also, there is a rise in creep stiffness and a reduction in the creep rate by increasing the percentage of the above polymers.

\section{Data Availability}

The data used to support the findings of this study are included within the article. 


\section{Conflicts of Interest}

The authors declare that they have no conflicts of interest.

\section{References}

[1] S. A. Tahami, A. F. Mirhosseini, S. Dessouky, H. Mork, and A. Kavussi, "The use of high content of fine crumb rubber in asphalt mixes using dry process," Construction and Building Materials, vol. 222, pp. 643-653, 2019.

[2] G. H. Shafabakhsh, M. Sadeghnejad, and Y. Sajed, "Case study of rutting performance of HMA modified with waste rubber powder," Case Studies in Construction Materials, vol. 1, pp. 69-76, 2014.

[3] H. Ziari, T. Akbari, H. Farahani, and A. Goli, "The effect of Lucobit polymer on bitumen performance," Petroleum Science and Technology, vol. 34, no. 6, pp. 512-516, 2016.

[4] S. Rezaei, H. Ziari, and S. Nowbakht, "Low temperature functional analysis of bitumen modified with composite of nano- $\mathrm{SiO}_{2}$ and styrene butadiene styrene polymer," Petroleum Science and Technology, vol. 34, no. 5, pp. 415-421, 2016.

[5] M. Garcia-Morales, "Effect of waste polymer addition on the rheology of modified bitumen," Fuel, vol. 85, no. 7-8, pp. 936-943, 2006.

[6] S. N. Nemade and P. V. Thorat, "Utilization of polymer waste for modification of bitumen in road construction," Scientific Reviews and Chemical Communications, vol. 2, no. 3, pp. 198-213, 2013.

[7] M. Ameri, A. Mansourian, and A. H. Sheikhmotevali, "Laboratory evaluation of ethylene vinyl acetate modified bitumens and mixtures based upon performance related parameters," Construction and Building Materials, vol. 40, pp. 438-447, 2013.

[8] C. Fang, R. Yu, Y. Li, M. Zhang, J. Hu, and M. Zhang, "Preparation and characterization of an asphalt-modifying agent with waste packaging polyethylene and organic montmorillonite," Polymer Testing, vol. 32, no. 5, pp. 953-960, 2013.

[9] B. Tóth, C. Varga, and L. Bartha, "Olefin-maleic-anhydride copolymer based additives: a novel approach for compatibilizing blends of waste polyethylene and crumb rubber," Waste Management, vol. 38, pp. 65-71, 2015.

[10] C. Brovelli, L. Hilliou, Y. Hemar, J. Pais, P. Pereira, and M. Crispino, "Rheological characteristics of EVA modified bitumen and their correlations with bitumen concrete properties," Construction and Building Materials, vol. 48, pp. 1202-1208, 2013.

[11] Z. A. A. Sakinah, C. T. Ratnam, A. L. Chuah, and T. C. S. Yaw, "Effect of mixing conditions on the tensile properties of ethylene vinyl acetate/waste tire dust (EVA/WTD) blend," Polymer-Plastics Technology and Engineering, vol. 48, no. 11, pp. 1139-1142, 2009.

[12] S. Saoula, K. Ait Mokhtar, S. Haddadi, and E. Ghorbel, "Improvement of the performances of modified bituminous concrete with EVA and EVA-waste," Physics Procedia, vol. 2, no. 3, pp. 1319-1326, 2009.

[13] A. A. Yousefi, "Rubber-polyethylene modified bitumens," Iranian Polymer Journal (English Edition), vol. 13, pp. 101112, 2004.

[14] M. Arabani, S. A. Tahami, and G. H. Hamedi, "Performance evaluation of dry process crumb rubber-modified asphalt mixtures with nanomaterial," Road Materials and Pavement Design, vol. 19, no. 5, pp. 1241-1258, 2018.
[15] N. Tabatabaee, "Evaluation of performance grading parameters for crumb rubber modified asphalt binders and mixtures," in Proceedings of the 7th international RILEM symposium on advanced testing and characterization of bituminous materials, Rhodes, Greece, May 2009.

[16] F. Zhang and C. Hu, "The research for crumb rubber/waste plastic compound modified asphalt," Journal of Thermal Analysis and Calorimetry, vol. 124, no. 2, pp. 729-741, 2016.

[17] B. Sengoz and G. Isikyakar, "Evaluation of the properties and microstructure of SBS and EVA polymer modified bitumen," Construction and Building Materials, vol. 22, no. 9, pp. 1897-1905, 2008.

[18] Z. B. Yildırım and M. Karacasu, "Modelling of waste rubber and glass fibber with response surface method in hot mix asphalt," Construction and Building Materials, vol. 227, Article ID 117070, 2019.

[19] R. M. Badri, M. Sutanto, and M. K. Alobaidi, "Investigating the rheological properties of asphalt binder incorporating different crumb rubber contents based on a response surface methodology," Journal of King Saud University-Engineering Sciences, 2020.

[20] E. Baskent Aydemir and M. H. Ozkul, "Investigation of effect of bitumen chemical composition, elastomeric polymer and paraffin wax additives on the properties of bitumen by using response surface method," Construction and Building Materials, vol. 234, Article ID 117414, 2020.

[21] F. H. Khairuddin, M. Y. Alamawi, N. I. M. Yusoff, K. H. Badri, H. Ceylan, and S. N. M. Tawil, "Physicochemical and thermal analyses of polyurethane modified bitumen incorporated with Cecabase and Rediset: optimization using response surface methodology," Fuel, vol. 254, Article ID 115662, 2019.

[22] A. Jiménez del Barco Carrión, A. Subhy, M. A. Izquierdo Rodriguez, and D. Lo Presti, "Optimisation of liquid rubber modified bitumen for road pavements and roofing applications," Construction and Building Materials, vol. 249, Article ID 118630, 2020.

[23] A. Usman, "Irradiated polyethylene terephthalate fiber and binder contents optimization for fiber-reinforced asphalt mix using response surface methodology," Ain Shams Engineering Journal, vol. 12, 2020.

[24] H. F. Haghshenas, A. Khodaii, A. Mehrara, M. H. Dehnad, and A. S. Ahari, "Frequency and temperature interactive effects on hot mix permanent deformation using response surface methodology," Journal of Materials in Civil Engineering, vol. 26, no. 6, Article ID 06014003, 2014.

[25] A. Ameri, "Laboratory evaluating of physical and rheological properties of modified bitumen containing crumb rubber and EVA," Journal of Transportation Infrastructure Engineering, vol. 6, no. 3, pp. 1-12, 2020.

[26] M. Panda and M. Mazumdar, "Engineering properties of EVA-modified bitumen binder for paving mixes," Journal of Materials in Civil Engineering, vol. 11, no. 2, pp. 131-137, 1999.

[27] O. González, M. E. Muñoz, A. Santamaría, M. Garćia-Morales, F. J. Navarro, and P. Partal, "Rheology and stability of bitumen/EVA blends," European Polymer Journal, vol. 40, no. 10, pp. 2365-2372, 2004.

[28] M. R. Keymanesh, H. Ziari, B. Damyar, and N. Shahriari, "Effect of waste EVA (ethylene vinyl acetate) and waste CR (crumb rubber) on characteristics of bitumen," Petroleum Science and Technology, vol. 35, no. 22, pp. 2121-2126, 2017. 